\title{
O AUTORITARISMO INSTITUCIONAL E A EXTINÇÃO DO IESAE
}

\author{
Maria de Lourdes de Albuquerque Fávero*
}

\begin{abstract}
RE SU M 0: O trabalho objetiva situar as origens, o percurso de construção e desenvolvimento do Instituto de Estudos Avançados em Educação (IESAE/ FGV), no período de 1971 a 1990. Analisa, especialmente, a extinção desse Instituto, após cerca de 20 anos de funcionamento, com conceito A em sucessivas avaliações da CAPES e classificado por essa agência e o CNPQ entre os melhores mestrados em educação no país. Situa a posição autoritária dos dirigentes da FGV com relação à extinção do IESAE, assim como a reação de vários atores e entidades representativas da sociedade civil - professores, alunos, políticos, intelectuais etc. - que se posicionaram contra 0 fechamento desse Instituto pela Fundação G etúlio Vargas. Conclui mostrando que a experiência do IESAE constituiu um marco no sentido de integrar pensamento e ação no estudo e na pesquisa de nossa realidade educacional, tendo em vista seu diagnóstico e 0 encaminhamento de soluções.
\end{abstract}

Palavras-chave: IESAE/ FGV. Mestrado em educação. Ensino e pesquisa. Extinção.

\section{INSTIIUIIONAL AUIHORITARIAN THRUST AND THE EXTINCTION OF THE IESAE}

A BST RA C T : The present study aims to discuss the origins, the construction and the development of the Institute of Advanced Studies in Education (IESAE/ FGV), between 1971 and 1990. It particularly focuses on the extinction of that Institute, after not only having been in action for around twenty years, but also having received the concept A in successive evaluation exercises by CAPES, as well as having been classified as one of the best Master courses by both that agency and CNPQ. It discusses the authoritarian position of the directors of the FGV concerning the extinction of the IESAE, as well as the

Livre-docente em Educação pela PUC-RIO, coordenadora e professora titular do mestrado em educação da UCP; coordenadora do PROEDEs/ UFRJ. E-mail: favero@ infolink.com.br

E duc. Soc., Campinas, vol. 24, n. 85, p. 1257-1275, dezembro 2003 
reaction of several actors and representative entities of the civil society, such as teachers, students, politicians, intellectuals and others, against that action taken by the G etulio Vargas Foundation (FGV). It concludes by emphasising the crucial role of the IESAE experience, which represented a hallmark in the process of integration of thought and action in the study and research of our educational reality, contributing both to diagnose and to help solve its problems.

Key words: IESAE/ FGV. Master in education. Teaching and research. Extinction.

\section{Preliminares}

E ste artigo é um dos resultados da pesquisa 0 IE SA E: origens, desenvolvimento e extinção, concluída no início deste ano. Ao término do relatório do projeto, uma questão colocou-se: 0 que 0 autoritarismo institucional pode ser capaz de fazer para demolir uma experiência educacional, como no caso a do Instituto de Estudos Avançados em Educação (IESAE) da Fundação Getúlio Vargas (FGV), que durante cerca de duas décadas desenvolveu trabalho de valor acadêmicocientífico reconhecido nacionalmente? Partindo desse questionamento, procuro situar não apenas a criação desse Instituto, as transformações nele ocorridas, seu desenvolvimento, mas sobretudo o significado e os problemas decorrentes de sua extinção.

Como assinalado em outros estudos (Fávero, 2001 e 2002), no decorrer da pesquisa procurou-se demarcar os caminhos vividos pelo IESAE. Para tanto, buscou-se captar e compreender, por meio de fontes textuais, o discurso desse Instituto, deixando que ele falasse de si, mediante sua proposta de mestrado, suas pesquisas, seus cursos de especialização, sua produção científica.

Isso posto, não se pode esquecer de que esse Instituto foi criado em pleno regime militar, período de nossa história marcado por forte repressão, pelo controle político e ideológico por parte do governo com relação às instituições educacionais e científicas. Como assinala José Américo Pessanha, filósofo e professor do IESAE, nesse contexto: "A mordaça silenciadora e algumas vezes a própria cicuta foram impostas sobretudo a pessoas. E o estrago foi imenso, os prejuízos irrecuperáveis, as seqüelas profundas" (Pessanha, 1990, p. 7). O poder podia se manifestar nas instituições educacionais, mas não procedia delas, nem a elas se circunscrevia. Tal situação vai persistir 
até o final dos anos de 1970, quando foram dados os primeiros passos com vistas à abertura política, com destaque para a promulgação da Lei da Anistia.

Em contrapartida, não se pode desconhecer que, mesmo em contexto adverso, a atuação de vários professores e pesquisadores de pensamento aberto influíram criativamente na dinâmica desse Instituto, a começar pela prática docente em sala de aula e na pesquisa, como também pela participação em diferentes órgãos, como 0 Comitê Assessor do CNPQ, a Comissão de Avaliação da CAPES, grupos de trabalho da FINEP e do INEP, bem como no Conselho Editorial da Revista Brasileira de E studos Pedagógicos e de outros periódicos educacionais. Importa registrar, também, que 0 IESAE sediou, em diferentes momentos, a Presidência e a Secretaria-Geral da ANPED, a qual contou efetivamente com a participação de docentes de seus quadros, cuja colaboração se fez sentir tanto nas comissões organizadoras das Conferências Brasileiras de Educação como nos debates sobre questões fundamentais, por ocasião da Assembléia Nacional Constituinte, que culminou com a promulgação da Constituição de 1988 (FGV/ IESAE, 1990, p. 7-8).

E mbora o projeto de criação do IESAE/ FGV apareça como resultado do trabalho da comissão antes mencionada, é sabido que esse Instituto se estruturou a partir das idéias de Anísio Teixeira, com base em três projetos fundamentais: a) constituir-se em centro de análise e prospecção da conjuntura educacional brasileira; b) consolidar um curso de mestrado em educação; e c) oferecer cursos intensivos de especialização sobre planejamento e administração de sistemas educacionais (Teixeira, 1969).

Para Teixeira, "a necessidade do estudo de pós-graduação não decorre apenas do progresso do conhecimento humano, mas de suas aplicações diretamente na ocupação e na vida, criando situações que requerem estudo e pesquisa para se dirigir o processo de aprendizagem contínua, de educação permanente". E acrescenta: "É essa tarefa de estudos e pesquisas que deseja a Fundação G etúlio Vargas empreender, criando para esse fim, em nível de pós-graduado, um instituto de estudos avançados em educação" (idem, ibid., p. 6-7).

Em 1ํ de janeiro de 1971, por meio da Portaria ํㅡㄴ 1, assinada pelo presidente da FGV, foram designados os professores Luiz Alves de Mattos, Joaquim de Faria Góes, Anísio Teixeira e José de 
Faria Góes Sobrinho para, sob a presidência do primeiro, constituírem a comissão encarregada de estudar as possibilidades e apresentar projeto de criação de um Centro de Estudos de Pós-Graduação de Educação, na FGV. Analisando-se fontes documentais textuais do IESAE, pode-se afirmar que havia, por parte da Fundação G etúlio Vargas, interesse em criar esse Instituto, naquele momento.

Neste sentido, um dado que vem reforçar essa afirmação é o convênio firmado em 7 de março de 1971 entre a FGV e a Subsecretaria de Cooperação Internacional (suBin), do Ministério do Planejamento e Coordenação-Geral. D e acordo com esse Convênio, a Fundação obrigava-se a tomar, entre outras, as seguintes providências para a organização desse Instituto: fornecer instalações físicas; designar pessoal de direção, administração e professores de seu quadro, como também contratar docentes que se fizessem necessários à implantação dos cursos; realizar entendimentos no sentido de obter assistência técnica de organismos internacionais, de países e de universidades estrangeiras, na organização dos cursos e das pesquisas; obter de entidades oficiais brasileiras recursos previstos nos planos do governo para financiamento de cursos de pós-graduação. A suBin, por sua vez, obrigar-se-ia a assegurar à Fundação o montante de Cr\$ 600.000,00 (seiscentos mil cruzeiros) durante os anos de 1971 e 1972, em parcelas a serem posteriormente acordadas, destinado ao custeio do Instituto na fase de sua implantação (Convênio FGv/ suBIN, 1971).

Em 1ํㅡㄹ de junho de 1971, mediante a Portaria ํㅡ 33, foi criado o Instituto de Estudos Avançados em Educação, tendo por objetivo "a realização de estudos, pesquisas e ensino em nível de pós-graduação na área de educação". Por essa mesma portaria foi designado seu diretor e uma Comissão de Planejamento. Na primeira sessão ordinária, o professor Luiz Alves de Mattos, como diretor, apresentou os membros que comporiam a equipe operacional e de apoio aos trabalhos da comissão. Merece destaque a indicação do professor D urmeval Trigueiro Mendes, como assessor técnico. Durante as primeiras reuniões realizadas, entre outros assuntos, foram discutidas as propostas curriculares das áreas de concentração do curso de mestrado: filosofia da educação, administração de sistemas escolares e psicologia educacional, constantes do Regimento aprovado em agosto de 1972. 
Papel e significado do mestrado do IESAE

O curso de mestrado, o segundo grande projeto do IE SA E, objetivava promover "a capacitação técnica necessária à reflexão crítica sobre a realidade socioeducacional brasileira, bem como a qualificação de profissionais capazes de contribuir para a renovação do sistema educacional em função de sua melhoria qualitativa" (FGV/ IESAE, 1990, p. 2). Para tanto, adotava como critérios metodológicos a análise da realidade educacional brasileira, a partir de diferentes posições teóricas, e a realização de pesquisas aplicadas que permitissem 0 exame das políticas e das propostas educacionais.

Concluída em maio de 1972 a fase de planejamento e recrutamento de pessoal docente e administrativo, o IESAE deu início a seu programa de trabalho, comunicando a abertura de inscrições para candidatos ao mestrado e começando suas atividades em agosto de 1972. Foram selecionados 54 candidatos provenientes de 14 estados. 0 mestrado inicia com três áreas de concentração, caracterizando-se como um curso de caráter nacional, com alunos de quase todo o país. Apesar de muito procurado por professores, sobretudo do ensino superior, a preferência da maioria dos candidatos, nos primeiros anos, volta-se para administração, gestão de instituições e sistemas educacionais. Como decorrência, é expressivo o número de mestres saídos do IESAE que, continuando a atuar no magistério, passaram a ocupar posições de destaque em universidades públicas e privadas, nos centros de formação profissional, nas Secretarias Estaduais e Municipais de Educação, bem como em organizações não-governamentais (FGV/ IESAE, 1992, p. 1).

Em 1974, o mestrado foi reconhecido pelo Conselho Federal de Educação, projetando-se como um dos melhores cursos da área no país, principalmente pela abordagem interdisciplinar possibilitada pela filosofia e pelas disciplinas básicas das ciências sociais, bem como pela configuração especial dada à pesquisa e sua relação com o ensino. Esse curso, de agosto/ 1972 a junho/ 1990, matriculou 716 alunos, em 13 turmas anuais. No momento de sua extinção tinha mais de 100 alunos regularmente matriculados (FGV/ IESAE, 1990). A lém dessas turmas, realizou em sua sede, em convênio com o Programa de Desenvolvimento do Ensino Médio (mec/ Prodem), um curso de mestrado específico para 15 professores de escolas técnicas federais. Assumiu, também, duas turmas "fora de sede", compostas por pro- 
fessores das universidades federais de G oiás e do Maranhão. Por exigência da CAPES, no período, parte significativa do currículo foi oferecida nessas universidades, e os mestrandos integraram-se posteriormente às turmas regulares, especialmente para a elaboração e defesa de suas dissertações.

Q uanto ao primeiro projeto, constituir-se em um Centro de A nálise de Prospecção da C onjuntura E ducacional Brasileira, embora tenha sido previsto nas disposições transitórias do Regimento, não chegou a ser instituído formalmente. A análise da documentação, no entanto, permite inferir que 0 IESAE não deixou de dar sua contribuição, mediante estudos e pesquisas junto de instituições públicas ou particulares. Tais atividades vão ao encontro do que estabelece o Regimento desse Instituto, ao dispor que 0 IESAE teria por finalidades: "promover a investigação no campo da Educação, bem como realizar, por si ou em colaboração com outros órgãos ou entidades, as pesquisas necessárias à elaboração de diagnósticos, segundo critérios analíticos e prospectivos, da situação educacional brasileira, em âmbito regional e nacional." (Art. 10, inciso I).

No mesmo Regimento, o artigo 1므, inciso II preceituava, ainda, que 0 IESAE fosse instituído como "um órgão de pesquisa e ensino", devendo:

Formar e aperfeiçoar, em nível de estudos pós-graduados, pesquisadores, professores universitários, administradores e outros especialistas em Educação, capacitados para identificar e equacionar a problemática educacional brasileira, e a contribuir para a formulação da política educacional do País e para o progresso das ciências da Educação.

E, no artigo 2o, dispunha: "O ensino no IESAE será ministrado em nível de pós-graduação, em bases teóricas e experimentais, mediante a associação ensino-pesquisa, dentro dos princípios estatuídos na legislação vigente".

A proposta inicial de um programa de pesquisa a ser desenvolvido pelo IESAE foi apresentada, em 1972, por D urmeval, abrangendo "três aspectos essenciais: a filosofia da pesquisa, a estratégia e a articulação com 0 ensino" (Trigueiro Mendes, 1972, p. 250). Para ele, a pesquisa seria considerada a substância da pós-graduação, devendo priorizar a análise da política educacional e do progresso das ciências da educação no país. Sem menosprezar a pesquisa empírica, afirma 
que, no IESAE, ela deveria se caracterizar "pela reflex ão filosófica, em busca das raízes de inteligibilidade da educação, de suas categorias e de seu processo, bem como pelo esforço de síntese". Tal síntese, no caso, significava: "A integração das ciências entre si, e das áreas com a política educacional". Em sua proposta, Durmeval faz um alerta que se constitui em verdadeira diretriz: "Não imaginamos, entretanto, a obra do pensamento separada da pesquisa teórica e da pesquisa empírica". Embora aceitando que a pesquisa no IESAE deveria centrarse nas áreas de concentração: "Filosofia da Educação (incluindo uma parte histórica), Administração Educacional e Psicologia Educacional", para ele, "não se tratavam, evidentemente, de três disciplinas, mas de três campos bastante abrangentes", cuja integração poderia oferecer uma base para 0 trabalho interdisciplinar, desde que procurasse incorporar, sempre que necessário, a contribuição de pesquisadores de outros institutos, dentro e fora da FGV (idem, ibid.). Nesta perspectiva, defende a existência de duas grandes linhas de pesquisa: "Uma motivada pelas necessidades educacionais do país e pelas eventuais 'encomendas' das instituições (por ele denominada de linha A) e a outra requerida pelos programas do curso (linha B). A primeira seguiria os acontecimentos, enquanto a segunda se ordenaria de acordo com a lógica e o ritmo do currículo" (idem, ibid.). No que se refere ao ensino, apresentava uma reflexão que até os dias atuais continua sendo um desafio: "A característica essencial da pós-graduação é a elaboração e não a informação"; caracteriza-se pelo trabalho autônomo do aluno (mesmo em equipe), sob a orientação de professores e em forma de pesquisa (idem, ibid., p. 257).

Essa proposta, contudo, em termos institucionais somente se concretizará em 1974, quando foi criada a Coordenação de Pesquisa. A partir daí, três eixos de trabalho desenvolveram-se concomitantemente:

a) pesquisa acadêmica, realizada por um professor com a participação de mestrandos, sobre tema de livre escolha, sem financiamento de agência externa e também sem recursos adicionais da própria Instituição; b) estudo e pesquisa de alunos para cumprir o requisito da dissertação; c) pesquisa com apoio financeiro de agências externas, através de convênio institucional. (Calazans et al., 1980, p. 3)

O exame dos relatórios disponíveis revela que, até meados dos anos de 1980, o IESAE contou com recursos financeiros substanciais, 
provenientes de alguns convênios de grande porte celebrados com 0 MEC (DAU, CAPES, INEP, FNDE), com o Ministério do Trabalho, por intermédio de sua Secretaria-Geral, com 0 CNPQ e 0 IPEA/ CNRH, e especialmente com a FINEP/ FNDCT, os quais davam suporte a projetos de pesquisa e à contratação de novos professores. A partir desse período, sucessivas crises financeiras do Estado brasileiro tiveram sérias repercussões na FGV, agravadas com a retração das agências financiadoras, 0 que provocou a diminuição dos projetos de pesquisa institucionais do IESAE e acarretou a descontinuidade dos trabalhos (FGV/ IESAE, 1992, p. 5). É pertinente observar que, de 1983 a 1987, cada pesquisador passou a trabalhar numa pesquisa, alguns com bolsa do CNPQ, outros com pequenos financiamentos institucionais.

O levantamento da produção no período de 1975 a 1990 indica que os docentes propuseram cerca de 100 projetos de pesquisa, dos quais foram concluídos 80 e em torno de 20 se encontravam em desenvolvimento, quando da extinção do IESAE. Desses projetos, cerca de $50 \%$ tiveram financiamento dos órgãos acima citados, além de secretarias estaduais de Educação, entre elas a do Rio de Janeiro e de Macapá (FGV/ IESAE, 1990, p. 4). Como produtos das pesquisas desenvolvidas, eram sistematicamente elaborados relatórios, produzidos artigos, publicados na Revista Fórum E ducacional/ IE SA E / FG V e em outros periódicos nacionais. Delas derivaram, também, várias dissertações dos mestrandos e teses de doutorado de professores. Alguns desses produtos foram transformados em livros.

Retomando a caracterização de Durmeval, no que diz respeito às pesquisas motivadas pelas necessidades educacionais, inclusive como assessorias a programas governamentais, verifica-se que foi marcante a atuação do IESAE, sobretudo até meados dos anos de 1980, por meio de amplos projetos que originaram produtos significativos. Como assinala Cândido Grzybowski (1988, p. 30), "o IESAE objetivamente inovou no campo da pesquisa educacional no Brasil".

O terceiro projeto - cursos de especialização - compreendeu, inicialmente, seis cursos em planejamento e administração educacional para os quadros técnicos de secretarias estaduais e municipais de Educação, assim como para professores universitários, realizados de 1973 a 1975, apoiados por convênio celebrado entre o Departamento de Assuntos Universitários (DAU) do MEC e 0 IESAE/ FGV. Os cursos tinham caráter regional e, com exceção do primeiro, foram realizados em regime de internato, com um mês de duração cada: a) Região Sudeste - 
Guanabara, Rio de Janeiro, Minas G erais e Espírito Santo, de 17/ 9 a 12/ 10 de 1973, no Rio de Janeiro; b) Região N orte - Amazonas, Pará, Acre e territórios de Roraima, Amapá, nov./ dez. de 1973, em Manaus; c) Parte Setentrional do N ordeste - Maranhão, Piauí, Ceará, Rio Grande do Norte e Paraíba, abr./ 74, em João Pessoa; d) Parte do Sul do N ordeste - Pernambuco, Sergipe, Alagoas e Bahia, jul./ 74, em Salvador; d) Região Sul - Paraná, Santa Catarina e Rio Grande do Sul, mais 0 estado de São Paulo, nov./ dez. de 1974, em Viamão; e) Região C entro-0 este - Distrito Federal e os estados de Goiás e Mato Grosso, ago./ set. de 1975, em G oiânia. Em todos esses cursos, mestrandos participavam como monitores, auxiliando nas disciplinas e na organização administrativa. D esses cursos eram selecionados os melhores alunos para o mestrado, o que contribuiu de modo efetivo para projetar 0 IESAE em plano nacional.

Pelo Projeto III, também, com financiamento do Programa de D esenvolvimento do Ensino Médio (MEC/ PRODEM), além do curso de mestrado específico para 15 professores de escolas técnicas, no Rio de Janeiro, o IESAE promoveu, entre 1975 e 1980, 4 cursos de aperfeiçoamento, visando à formação de quadros para os CEFETS: em Campos, Rio de Janeiro, Belém e João Pessoa. Com apoio financeiro do Programa de Melhoria do Ensino Isolado (MEC/ PROMESI), realizou vários seminários de administração e planejamento de instituições isoladas, no período de 1976-1978 (FGV/ IESAE, 1992, p. 4). A té o ano de 1990, quando foi declarado extinto, o Instituto de Estudos Avançados em Educação/ FGv desenvolveu também uma linha de cooperação técnica com as secretarias estaduais e municipais de Educação, mediante seminários, cursos e assessorias.

Q uanto à produção científica, dados da pesquisa permitem afirmar que foram produzidos em torno de 740 títulos, incluindo: 4 livros publicados pela FGV/ IESAE e outros em várias editoras, sendo 0 mais importante Filosofia da educação brasileira, resultado da pesquisa sobre essa temática, coordenada por D urmeval Trigueiro Mendes. Há também muitos artigos publicados em periódicos e grande número de relatórios de pesquisa, aos quais se devem acrescentar 393 dissertações de mestrado defendidas e aprovadas. No conjunto das atividades do FGV/ IESAE, com vistas à realização de seus objetivos programáticos, as dissertações de mestrado representam uma dimensão de especial significado, ao lado da produção das pesquisas dos docentes e da prática de ensino. Merece destaque, ainda, a Revista Fórum 
E ducacional, criada em 1977, com periodicidade trimestral, que publicava trabalhos realizados no próprio Instituto, abrangendo também colaborações de professores de outra instituições.

\section{A extinção do IESAE, um feito da "razão empresarial"}

Após cerca de 20 anos de funcionamento, tendo recebido conceito A nas sucessivas avaliações da CAPES e classificado por essa agência e 0 CNPQ entre os cinco melhores mestrados em educação no país, 0 IESAE, por meio da Portaria no 24, de 20 de junho de 1990, simultaneamente com outros sete órgãos da FGV, foi declarado extinto. Essa medida ocorre quando o Instituto estava em pleno processo de reestruturação administrativa e acadêmica, com o objetivo de conferir-lhe maior eficiência e produtividade, definindo novas linhas de pesquisa, estudos e projetando a criação do doutorado. Em complementação à portaria anterior, em 23 de julho do mesmo ano, o presidente da FGv baixa outra, determinando que a Escola Brasileira de Administração Pública (EBAP) e a Escola de Pós-Graduação em Economia (EPGE) passariam a ser "responsáveis temporariamente pelos cursos de pós-graduação stricto sensu, de órgãos cujas atividades foram extintas, devendo preservar ao máximo as características anteriores desses cursos, quanto aos aspectos técnico, científico e didático, inclusive quanto ao corpo docente e à sua coordenação". No caso do IESAE, temporariamente suas atividades de pesquisa, ensino e consultoria passariam a ser exercidas pela EBAP.

Em face do exposto, pode-se indagar: como garantir que essa unidade, por mais competente e reconhecida em termos acadêmicocientíficos em sua área específica de conhecimento, teria condições de preservar as características anteriores de um curso de mestrado de campo tão diverso como o IESAE em termos de ensino-pesquisa, sobretudo se pensarmos as áreas de concentração de filosofia da educação e de psicologia da educação?

É pertinente lembrar que a súbita extinção do IESAE e de mais outros órgãos da FGV significou uma "demolição não apenas do trabalho presente e da defesa da produção do passado, mas também demolição de horizontes futuros" (Pessanha, 1990, p. 7). Não se pode esquecer, também, de que 0 encerramento das atividades desses institutos, possivelmente, estava associado ao processo político- 
econômico vivenciado no país no início da década de 1990, como decorrência da política econômica do Governo Collor, e aos problemas de recursos financeiros gerados pela administração de convênios com as instituições de apoio à pesquisa. E mais, a FGV, cujo regime jurídico é de fundação de direito privado, sempre recebeu recursos públicos do governo federal, e com as novas medidas restritivas adotadas por aquele governo, diversas mudanças administrativas ocorreram nessa Fundação.

Analisando a extinção desses oito institutos da Fundação Getúlio Vargas, José Américo Pessanha observa com propriedade que "o perigo era o da progressiva construção de imenso deserto cultural, gerado por falta de irrigação e de despovoamento" (idem, ibid.). E complementa:

Modernização e contenção de gastos, eis o binômio usado retoricamente para justificar as sucessivas demolições. Na verdade, trata-se de estreitas e equivocadas acepções de modernidade, de investimento, de relação Estado e cultura. Mais: trata-se de incompreensão do que é arte, cultura e educação enquanto direitos humanos.

Importante lembrar: depois de 64, sofremos análogo esmagamento. Significativamente, as áreas mais atingidas foram também aquelas que os argutos renascentistas chamavam de humanidades. (Idem, ibid.)

Este filósofo e professor do IESAE observa ainda que se no pós64 "era declarada guerra ideológica, porque silenciava a consciência crítica", em 1990, as armas do autoritarismo aparecem "escamoteadas numa concepção supostamente científica", utiliza "conceitos de aparato acadêmico, falando em nome de uma racionalidade que se pretende modernizadora, mas que, na verdade, justamente por se querer universal e hegemônica, permanece atada ao já criticado cientificismo do século 19" (idem, ibid.).

Por força de liminar obtida na Justiça por 93 alunos do IESAE, representados pelo advogado Hermann Baeta, foi-lhes assegurado 0 direito de concluir o mestrado no Instituto em que se matricularam. $\mathrm{Na}$ "ação cautelar inominada com pedido de ação liminar", o advogado foi muito explícito e contundente: "A Lei nㅡ 5.540, de 28/11/ 1968, estabelece, no art. 24, ipsis litteris: 'O Conselho Federal de Educação conceituará os cursos de pós-graduação e baixará normas gerais para sua organização, dependendo de sua validade, no territó- 
rio nacional, de os estudos nele realizados terem os cursos respectivos credenciados por aquele órgão'”. E adverte:

Como se vê, com clareza, os cursos de pós-graduação não podem existir e funcionar ad libitum das direções das instituições a que estão vinculados. Ao contrário, dependem, sem nenhuma exceção, do credenciamento e recredenciamento do CFE (Conselho Federal de Educação), que é, como se sabe, um órgão integrado na estrutura acadêmico-administrativa do Ministério da Educação, da Administração D ireta da Presidência da República. (Baeta, 1990)

Em decorrência da liminar ganha pelos mestrandos na Justiça, foi baixada a Portaria nº 65, em 11 de dezembro de 1990, assinada pelo presidente da FGV, assegurando aos alunos que estavam produzindo suas dissertações ou ainda cursando disciplinas o direito de concluir 0 mestrado no Instituto em que se matricularam. G raças, também, ao apoio de várias entidades, associações científicas, universidades, secretarias de educação, ex-alunos etc. que se manifestaram, a Presidência da Fundação, ainda em dezembro desse mesmo ano, restabeleceu a "autonomia acadêmica" e a "relativa autonomia administrativa" do IESAE, mantendo, no entanto, a proibição de matrícula de novas turmas.

Entre os numerosos apoios recebidos para manutenção do IESAE, merece destaque 0 pronunciamento bastante enérgico da Comissão de Consultores da CAPES, dirigido ao presidente da FGV e à superintendente da Fundação, em 7 de dezembro de 1990. Após analisar o problema da extinção desse Instituto e tecer sérios comentários, a comissão assim se pronuncia:

A Comissão de Consultores da Área de Educação da CAPEs conclui que a decisão da direção executiva superior e do Conselho Diretor da FGv no sentido de extinguir 0 IESAE e seu Programa de Mestrado em Educação: 1) Consistiu em leviandade/ negligência por parte daqueles que não se preocuparam em apreciar, liminarmente, como manda o seu dever de dirigentes, os graves danos que tal ato inevitavelmente causaria aos ingentes esforços do país para desenvolver e aprimorar sua pós-graduação nos mais variados campos do conhecimento, e sobretudo naquelas instituições, como o IESAE, onde os investimentos realizados vêm sendo geridos com eficiência, situando-se portanto entre os mais produtivos sob todos os pontos de vista. 2) Embora leviana/ negligente, a tal decisão certamente poderá e será revertida, como recomenda o elementar bom senso esperado da direção superior da Fundação Getúlio Vargas, integrada por Celina Vargas do Amaral Peixoto Moreira Franco, Francisco D ornelles, Mário Henrique Simonsen (...), entre outros profissio- 
nais de tal ilustração e suposta preocupação com os rumos da educação brasileira. (G atti et al., 1990)

Com redução de quase $50 \%$ de seu corpo docente e dispensa radical de funcionários de seu quadro administrativo, as atividades do mestrado foram retomadas no início de 1991, com a oferta de disciplinas e a orientação das dissertações. Em 23 de janeiro daquele ano, por meio do Ato no 21, assinado por Jorge O scar Mello Flôres, vicepresidente em exercício da Superintendência-Geral, o professor Newton Lins Buarque Sucupira foi dispensado do cargo em comissão de coordenador-geral de Ensino, do IESAE, e, na mesma data, mediante 0 A to $n^{0}$ 22, foi designado para exercer o cargo em comissão de coordenador-geral do IESAE. Em razão da redução do corpo docente, tornou-se difícil o funcionamento dos departamentos, assim como 0 Conselho Coordenador, substituído por um Colegiado de Curso, constituído pelos professores em exercício e pela representação estudantil, presidido pelo coordenador-geral.

Em 20 de julho de 1992, o professor Newton Sucupira, após entendimentos com a presidente da CAPEs, professora Eunice Durham, encaminhou-lhe ofício acompanhado de uma Proposta de reestruturacão do IE SA E, solicitando apoio financeiro dessa agência de fomento (Sucupira, 1992). Em resposta, a presidente da CAPEs, por meio de documento datado de 31/7/ 1992, informa: "Mesmo reconhecendo 0 mérito da proposta não poderá atender à solicitação por não ser esta de iniciativa institucional". E acrescenta:

A CAPEs atua junto à pós-graduação com base em planos de desenvolvimento institucional, elaborados pelas instâncias acadêmicas e administrativas das IEs e discutidos com esta agência por seus mais altos responsáveis. Às prioridades desses planos devem corresponder a garantia de contrapartida institucional. No caso da solicitação do IESAE, não fica evidenciado o interesse da alta administração da FGV em implementá-la, principalmente se considerarmos que subsiste apenas a intenção institucional de manter o curso de mestrado até 1993.

(...) A lém dessa questão fundamental (...), o montante solicitado é extremamente elevado, ultrapassando qualquer possibilidade de apoio da CAPES, tendo em vista a dotação orçamentária. (Durham, 1992)

Há, no entanto, na Coleção IESAE/ FGV-PROEDES/ UFRJ, um documento manuscrito sem data, em papel timbrado da CAPES, assinado por Eunice R. Durham, no qual ela assim se expressa: 


\section{Prezados colegas}

Em relação à extinção do IESAE, acho que minha posição como Diretora da CAPEs torna difícil uma manifestação pública, que pareceria uma ingerência indevida do G overno Federal junto a uma fundação privada. Entretanto, mantive um contato pessoal com a Professora Celina, manifestando o interesse da cAPEs pelo Mestrado em Educação, que tem contado com o apoio desta instituição.

Atenciosamente, Eunice R. Durham (s/ d).

É pertinente observar também que, na 385a Sessão Ordinária do Conselho Diretor da FGV, realizada em 11/ 9/ 1990, a professora Celina Moreira Franco, após a discussão de outras matérias, "declarou haver ainda outro assunto a tratar (...), o da reivindicação de alunos ex-componentes do extinto IESAE no sentido de ser este reestruturado com uma redução do quadro e uma reformulação de propósitos". A respeito,

(...) o Conselheiro Vice-Presidente [observa que], embora reconhecendo ser interessante essa reformulação, manifestou-se contrário à idéia por diversas razões: 1) seria um precedente que invalidaria todo o esquema de redução de despesas da FGV, ora em desenvolvimento; 2) significaria um prêmio ao único grupo que eticamente teve um comportamento condenável, tanto em relação aos seus ex-dirigentes, com críticas acerbas que feitas agora são extemporâneas, no tocante à administração da FGV, contra a qual lançou pessoas e entidades e, através dos alunos, provocou dificuldades judiciais e complicações junto ao Conselho Federal de Educação; 3) não se justificaria, ainda, mesmo que não existissem as objeções anteriores, porquanto, segundo o orçamento apresentado, o órgão continuaria deficitário e incompatível com o atual regime de economia. D ebatida a matéria, o Conselho D iretor recusou a proposta e considerou, por unanimidade, não rever a decisão de extinção de determinados órgãos da Fundação. (FGV. Ata da 385a Sessão O rdinária do Conselho Diretor, 11/ 9/ 1990)

A posição do Conselho Diretor e, em especial, de seu vicepresidente criou sérias reações fora da Fundação. É o que demonstra o posicionamento do deputado federal do PDT, Lysaneas Maciel: "A desfaçatez e o desrespeito [da Fundação] foram a um ponto mais amplo quando o Sr. Flores, Vice-Presidente da entidade, ao justificar seu voto contrário, classificou o IESAE como único grupo que eticamente teve um comportamento condenável" (Maciel, 1990). 
Em contrapartida, o parecer dado pela área técnica da FINEP, à qual também foi encaminhada a referida Proposta de reestruturação do IE SAE, embora reconhecendo a relevância da experiência do IESAE, não é conclusivo.

Além de numerosos pronunciamentos, telegramas de repúdio à extinção do IESAE pela Fundação G etúlio Vargas, no dia 10 de agosto de 1990, realizou-se no Teatro Casa G rande um Ato da Sociedade Civil em D efesa da Educação e da Cultura. A mesa foi composta por: José Américo Pessanha (presidente); Barbosa Lima Sobrinho; Herbert de Souza (Betinho) e Hermann Assis Baeta. A relação de subescritores desse Ato é constituída de 331 pessoas.

Em fevereiro de 1994, por ocasião da defesa das últimas dissertações sob a responsabilidade do IESAE, após todas as tentativas de salvar esse Instituto, mais de 100 signatários assinaram o Manifesto in memoriam do IESA E/ FGV , enviado à imprensa, ao Poder Executivo, ao Legislativo e ao Judiciário:

Para que o passado não se apague, já que o futuro dura muito tempo (...)

Ao encerrar o último dia de trabalho do IESAE, que em sua história titulou aproximadamente 400 mestres, mais de mil especialistas, e cujos professores e técnicos produziram um imenso acervo de livros, artigos, relatórios de pesquisa e trabalhos de assistência técnica e intercâmbio nacional e internacional, os abaixo-assinados, presentes nas defesas públicas das três teses defendidas neste 28.02.94, querem registrar, não apenas o repúdio e a consternação face a este "massacre" a um dos mais expressivos institutos de pesquisa e pós-graduação em educação, mas alertar todos aqueles comprometidos com efetivos valores éticos e democráticos de que esta lógica necessita ser interrompida e as responsabilidades apuradas.

Finalizando, observam:

(...) Nosso apelo é no sentido de que os setores governamentais, que durante meio século permitiram, com o fundo público, construir o patrimônio da FGV, bem como organismos ligados à defesa da economia popular e aos direitos à educação eà cultura, se inteirem do que está ocorrendo. Por esta lógica, a péssima situação educacional e cultural de nosso país tenderá a se agravar. Por este caminho, demarcado pela exclusão, também os anseios de uma sociedade democrática ficam cada vez mais distantes.

Em 1998, convidada a dar entrevista sobre o IESAE, ao lado de outras 38 pessoas que deram seus depoimentos a respeito de suas ex- 
periências na FGV, publicadas no livro $\mathrm{F}$ undação $\mathrm{G}$ etúlio $\mathrm{V}$ argas; concretização de um ideal (1999), Julieta Calazans registra seu depoimento sobre o papel e o significado do IESAE:

A memória tem sentido na medida em que permite pensar o presente; portanto vale resgatar a experiência do IE SAE para pensar a educação brasileira hoje (...). Vamos pontuar nossa percepção: primeiro, essa densa experiência foi arrancada da sociedade com a tensão de uma rocha, num contexto político-social de violência institucional, nas décadas de 70 e 80. Isso exigiu habilidade, competência, estratégia, firmeza de projetos, no âmbito ético e político, científico e técnico. Segundo, foi necessário um fecundo debate e uma imensa participação para que essa experiência se produzisse pela via democrática. Terceiro, houve um abortamento da experiência pela regressão neoliberal, provocada pela privatização. 0 IESAE era uma proposta nacional. Com um corpo diversificado nos aspectos de formação acadêmica, de interesses socioeducacionais, de perspectiva e visão de mundo. Era um estímulo para pensar o Brasil, uma escola de práxis.(...).

O fechamento do IESAE pode ser tomado como um ponto de inflexão na política educacional brasileira (...). 0 que mais posso dizer? Uma das coisas mais importantes do IESAE era a capacidade de ousar. E uma das coisas que nos fez sentir aprisionados na época em que 0 IESAE foi extinto foi esta: não tínhamos mais como ousar. Cortaram a nossa cabeça, passamos a não existir. (Calazans, 1999, p. 220-221)

\section{Concluindo}

A pesquisa realizada sobre 0 IESAE permite afirmar que, na história da educação brasileira, experiência como essa, apesar das contradições vivenciadas, constituiu realmente um marco no sentido de integrar pensamento e ação no estudo e na pesquisa de nossas realidades, com vistas a seu diagnóstico e ao encaminhamento de soluções. Mas, como aconteceu com outras instituições no país - por exemplo, o Centro Brasileiro de Pesquisas Educacionais do INEP -, a experiência foi interrompida.

Retomando mais uma vez José Américo Pessanha, quando critica 0 autoritarismo da Fundação G etúlio Vargas, no caso da extinção de oito institutos, concordo com sua observação: faltava a essa política o senso da diferença; pretendendo ser modernizadora, ela se baseava em conceitos obsoletos. Faltava-lhe principalmente visão do que era 
o social, o político, o cultural, o artístico, reduzindo arte, cultura e educação ao espetáculo, à lucratividade (1990, p. 7).

Recebido em julho de 2003 e aprovado em outubro de 2003.

\section{Referências bibliográficas}

BAETA, H.A. Ação com pedido de liminar em favor de 93 alunos do IESAE/ FGV, 18/ 7/ 90.

BRASIL. Ministério do Planejamento e Coordenação Geral. Subsecretaria de Cooperação Internacional. Convenio entre a FGV e a SUBIN, firmado em 07/ 03/ 1971.

CALAZANS, M.J.C. et al. A pesquisa no Instituto de E studos A vançados em E ducação. Rio de Janeiro: fGV/ IESAE, 1980.

CALAZANS, M.J.C. O IESAE: formando professores e operadores da educação. In: D'A raújo., M.C. (O rg.). Fundação $G$ etúlio V argas: concretização de um ideal. Rio de janeiro: FGV, 1999. p. 213-221.

DURHAM, E.R. DG S 094/ 92, da presidente da CAPES ao professor Newton Sucupira, coordenador-geral do IESAE. Brasília, D F, 31/ 07/ 1992.

DURHAM, E.R. Documento manuscrito dirigido aos colegas do IESAE. [s.d.] 1p.

FÁVERO, M.L.A. A experiência do IESAE/ FGV: das origens à construção. In: REUNIÃO ANUAL D A ANPED, 24., Caxambu, 2001. A nais da... Caxambu, 2001. CD-ROM

FÁVERO, M.L.A. Um olhar sobre o IESAE através de fontes documentais. In: CONG RE SSO LUSO-BRASILEIRO DE HISTORIA DA ED UCAÇÃ O, 4., Porto Alegre, 2002. CD-ROM

FÁVERO, M.L.A.; FÁVERO, O. O IESAE: resgate de uma história. M ovimento, n. 6, p. 23-39, set. 2002.

FUNDAÇÃO GETÚlIO VARGAS. Portaria n. 1, de 07/ 01/ 1971. D esigna os Góes Sobrinho para, sob a presidência do primeiro, constituírem a comissão encarregada de estudar as possibilidades 
e apresentar projeto de criação de um Centro de Estudos Pós-Graduados em Educação.

FUNDAÇÃO GETÚlIO VARGAS. Portaria n. 33, de 01/ 06/ 1971. Cria o IESAE (Instituto de Estudos Avançados em Educação) e designa seu diretor e a Comissão de Planejamento e Programação do Instituto.

FUNDAÇÃO GETÚLIO VARGAS. Regimento do IESA E, aprovado pela Portaria n. 54, em 18/ 08/ 1972.

FUNDAÇÃO GETÚliO VARGAS. Portaria n. 24, de 28/ 06/ 1990. Extingue órgãos e dá outras providências.

FUNDAÇÃO GETÚllO VARGAS. Portaria n. 28, de 23/ 07/ 1990. Dá providências para preservar cursos transferidos, tendo em vista disposições regulamentares.

FUNDAÇÃO GETÚlIO VARGAS. Ata da 385a Sessão Ordinária do Conselho Diretor da Fundação G etúlio Vargas, realizada em 11/ 09/ 1990.

FUNDAÇÃO GETÚliO VARGAS. Portaria n. 65, de 11/ 12/ 1990. A tende liminar de Justiça.

FUNDAÇÃO GETÚlIO VARGAS. Ato n. 21, de 23/ 01/ 1991. Dispensa o professor Newton Lins Buarque Sucupira do IESAE do cargo em comissão de coordenador-geral de Ensino do IESAE, por motivo de sua designação para outro cargo.

FUNDAÇÃO GETÚliO VARGAS. Ato n. 22, de 23/ 01/ 1991. Designa o professor Newton Lins Buarque Sucupira para o cargo em comissão de coordenador-geral do IESAE.

FUNDAÇÃO GETÚLIO VARGAS/ IESAE. IESAE: retrospectiva e perspectiva. Rio de Janeiro, jun. 1990. 15p. (mimeo.)

FUNDAÇÃO GETÚLIO VARGAS/ IESAE. Proposta de reestruturação do IESAE: $1^{0}$ documento. Rio de Janeiro, jan. 1992. 14 p. (mimeo.)

GATTI, B. et al. Pronunciamento da Comissão de Consultores da CA PE S da Á rea de E ducação, encaminhado ao presidente da FGV e à superintendente, em 07/ 09/ 1990, sobre a extinção do IESAE. 
GRZYBOWSKI, C. Elementos para uma proposta científico-pedagógica do IESAE. Boletim A N PE D, v. 10, n. 4, p. 29-31, jan./ mar. 1988.

MACIEL, L. Modernidade na educação. 0 D ia, 2 nov. 1990.

MANIFESTO in memoriam do IESAE/FGV. Rio de Janeiro, 28/02/ 1994.

PESSANHA, J.A.M. O novo autoritarismo científico. Jornal do Brasil, Rio de Janeiro, 29 set. 1990, Idéias/ Ensaios, p. 7.

SUCUPIRA, N. O fício n. 090/92, do coordenador-geral do IESAE à professora Eunice Durham, presidente da Fundação CAPEs. Rio de Janeiro, 20/ 07/ 1992.

TEIXEIRA, A. Caráter ex perimental dos estudos avançados dos problemas brasileiros da educação. Rio de Janeiro, 1969. 10p. (mimeo.)

TRIGUEIRO MENDES, D. Pesquisa e ensino no mestrado de educação. Revista Brasileira de E studos Pedagógicos, Brasília, D F, v. 58, n. 128, p. 249-264, out./ dez. 1972. 